\title{
Analysis of Erectile Responses to Imatinib in the Rat
}

\author{
Edward A. Pankey, George F. Lasker, Serap Gur, Wayne J. G. Hellstrom, and Philip J. \\ Kadowitz \\ Department of Pharmacology, Tulane University School of Medicine, New Orleans, LA; and the \\ Department of Urology, Tulane University School of Medicine, New Orleans, LA
}

\begin{abstract}
OBJECTIVE-To investigate the erectile and cardiovascular responses to the tyrosine kinase inhibitor imatinib in the rat.
\end{abstract}

MATERIALS AND METHODS-The effect of intracavernosal injection of imatinib on the intracavernosal pressure (ICP), ICP/mean arterial pressure (MAP) ratio, area under the curve, and duration of the increase in ICP and the effect of intravenous injection of imatinib on the MAP, cardiac output, and total peripheral resistance were investigated. The effect of the nitric oxide synthase inhibitor NG-nitro-L-arginine methyl ester on the responses to imatinib was investigated.

RESULTS-Intracavernosal injection of imatinib produced significant dose-related increases in the ICP, ICP/MAP ratio, area under the curve, and duration of the increase in ICP and decreases in the MAP. The erectile responses to imatinib were rapid in onset and short in duration. The erectile responses to imatinib were not significantly altered by NG-nitro-L-arginine methyl ester or cavernosal nerve crush injury, and imatinib was significantly less potent than the nitric oxide donor sodium nitroprusside in inducing erection. Intravenous injection of imatinib produced significant dose-related decreases in the MAP without significantly changing the cardiac output, and imatinib was significantly less potent than sodium nitroprusside in decreasing the MAP. Systemic vascular resistance was decreased in a significant dose-related manner, and the vasodilator responses to imatinib were not altered by NG-nitro-L-arginine methyl ester.

CONCLUSION-The present results have indicated that imatinib has significant erectile and systemic vasodilator activity in the rat that is not dependent on nitric oxide release. Another tyrosine kinase inhibitor, nilotinib, also increased the ICP and decreased the MAP in the rat. These data suggest that tyrosine kinases might play a constitutive role in maintaining penile tumescence and the baseline vasoconstrictor tone in the peripheral vascular bed.

Receptor tyrosine kinases are essential components of cell signal transduction pathways and play an important role in cell functions such as growth, differentiation, metabolism, and motility. These transmembrane receptors bind peptide ligands such as platelet-derived growth factor (PDGF) and catalyze the transfer of phosphate to tyrosine residues on protein substrates using adenosine triphosphate as a phosphate donor. ${ }^{1}$ Imatinib was initially identified in a program to develop PDGF inhibitors, but it also potently inhibits the stem cell factor receptor protein tyrosine kinase (KIT) and the nonreceptor tyrosine kinase Abl. ${ }^{1}$ Imatinib is effective in the treatment of chronic myelogenous leukemia. ${ }^{2}$ Imatinib has been shown to suppress smooth muscle contractions in isolated preparations from the guinea pig urinary bladder, rabbit corpora cavernosa, human prostate gland, human and rabbit

(C) 2013 Elsevier Inc. All Rights Reserved

Reprint requests: Philip J. Kadowitz, Ph.D., Department of Pharmacology, Tulane University School of Medicine, SL83, 1430 Tulane Avenue, New Orleans, LA 70112-2699. pkadowi@tulane.edu.

Financial Disclosure: The authors declare that they have no relevant financial interests. 
myometrium, and isolated pulmonary arteries from the rat. ${ }^{3-9}$ The observation that 3 different tyrosine kinase inhibitors had potent vasorelaxant properties in isolated pulmonary arteries suggests that tyrosine kinase signaling has an important role in regulating vascular smooth muscle contractile function. ${ }^{9}$ However, the effect of imatinib on erectile function and systemic vascular resistance in the rat have not been investigated. The present investigation was undertaken to investigate the responses to intra-cavernosal (IC) and intravenous (IV) injections of imatinib in the rat and to evaluate the role of nitric oxide synthase (NOS) and nitric oxide (NO) in mediating responses to the tyrosine kinase inhibitor imatinib. The results of these studies showed that imatinib has significant erectile and systemic vasodilator activity that is not dependent on NO release in the rat. These results can be interpreted to suggest that constitutive tyrosine kinase signaling might play a tonic role in maintaining penile tumescence and vasoconstrictor tone in the systemic vascular bed of the rat.

\section{MATERIAL AND METHODS}

The institutional animal care and use committee of Tulane University School of Medicine approved the experimental protocol used in these experiments, and all procedures were conducted in accordance with institutional guidelines. For these experiments, adult male Sprague-Dawley rats, weighing $290-410 \mathrm{~g}$, were anesthetized with thiobutabarbital (Inactin), $100 \mathrm{mg} / \mathrm{kg}$, intraperitoneally. Supplemental doses of thiobutabarbital were given intraperitoneally, as needed to maintain a uniform level of anesthesia. The body temperature was maintained with a heating lamp. The trachea was cannulated with a short segment of polyethylene (PE-240) tubing to maintain a patent airway, and the left carotid artery was catheterized with polyethylene (PE-50) tubing for measurement of the systemic arterial pressure. The intracavernosal pressure (ICP) was measured using a 25-gauge needle inserted into the left crus of the penis connected to polyethylene (PE-50) tubing filled with heparin. The systemic arterial pressure and ICP were measured using Namic Perceptor DT pressure transducers and a data acquisition system (Biopac MP 100A-CE, Santa Barbara, CA). The ICP, systemic arterial pressure, and mean systemic arterial pressure (MAP), obtained by electronic averaging, were continuously recorded and displayed and stored using a Dell personal computer. The left jugular vein was catheterized with polyethylene (PE-50) tubing for systemic administration of the drugs and fluids. A 26-gauge needle was placed in the right crus of the penis for administration of imatinib, nilotinib, and sodium nitroprusside (SNP). The maximal ICP in response to IC injection of the vasodilator agents or cavernosal nerve stimulation was measured at the peak of the erectile response. The area under the curve (AUC) and duration of the increase in ICP were measured to characterize the total erectile response.

The cardiac output was measured using the thermodilution technique with a Cardiomax II computer (Columbus Instruments, Columbus, $\mathrm{OH}$ ), as previously described. ${ }^{10} \mathrm{~A}$ known volume $(0.2 \mathrm{~mL})$ of room temperature $0.9 \%$ sodium chloride solution was injected into the jugular vein catheter, with the tip near the right atrium, and changes in blood temperature were detected using a $1.5 \mathrm{~F}$ thermistor microprobe catheter (Columbus Instruments) positioned in the aortic arch from the left carotid artery.

Cavernosal nerve stimulation was performed as previously described. ${ }^{11}$ For nerve stimulation, the bladder and prostate were exposed through a midline abdominal incision. The cavernosal nerve was identified posterolaterally to the prostate on 1 side, and a stainless steel bipolar stimulating electrode was placed on the nerve. The cavernosal nerve was stimulated with square wave pulses at a frequency of $16 \mathrm{~Hz}$, voltage of $5 \mathrm{~V}$, and pulse width of $5 \mathrm{~ms}$ for a duration of 60 seconds using a SD9 Stimulator (Grass Instruments, West Warwick, RI). A rest period of $\geq 5$ minutes was allowed between nerve stimulation trials. 
Nerve crush experiments were performed with three 15-second applications of 3-in. forceps to the cavernosal nerve $5 \mathrm{~mm}$ distally to the major pelvic ganglia.

Imatinib mesylate and nilotinib (Novartis, Basel, Switzerland) were dissolved in de-ionized water titrated to a pH of 5 and 2, respectively. NG-nitro-L-arginine methyl ester (L-NAME) and SNP were dissolved in $0.9 \%$ sodium chloride, and the solutions were frequently made. The doses of imatinib and nilotinib used were determined from previously published studies and pilot experiments. For the IC injections, the doses of imatinib, nilotinib, and SNP were prepared in a total volume of $200 \mu \mathrm{L}$ and were injected through the 26-gauge needle into the right crus.

The data are expressed as the mean \pm standard error and were analyzed using 1-way analysis of variance (ANOVA) and a Student's $t$ test for paired data. $P<.05$ was used as the criterion for statistical significance.

\section{RESULTS}

The effect of imatinib on erectile function was investigated in the rat, and these data are summarized in Figure 1. The IC injection of imatinib in doses of $0.1-10.0 \mathrm{mg} / \mathrm{kg}$ produced dose-related increases in the ICP $(5 \pm 1$ to $32 \pm 5 ; P<.05$, ANOVA), ICP/MAP ratio $(0.13 \pm$ 0.02 to $0.48 \pm 0.04 ; P<.05$, ANOVA), AUC ( $330 \pm 130$ to $3700 \pm 1100 ; P<.05$, ANOVA), and duration of the response ( $130 \pm 22$ to $500 \pm 120 ; P<.05$, ANOVA; Fig. 1A). The IC injections of imatinib also produced dose-related decreases in the MAP $(9 \pm 2$ to $24 \pm 3 ; P<$. 05, ANOVA; Fig. 1B). The effect of nilotinib, another tyrosine kinase inhibitor, on the ICP/ MAP ratio is shown in Figure 1C. The IC injection of nilotinib in doses of $1-10 \mathrm{mg} / \mathrm{kg}$ produced dose-related increases in the ICP $(11 \pm 2$ to $40 \pm 5 ; P<.05$, ANOVA), ICP/MAP ratio $(0.20 \pm 0.01$ to $0.49 \pm 0.07 ; P<.05$, ANOVA; Fig. 1C), and AUC (1213 \pm 446 to 5397 $\pm 867 ; P<.05$, ANOVA). The increases in ICP in response to the IC injection of imatinib and nilotinib were rapid in onset, ranging from 15 to 30 seconds. Very little delay was seen in the decrease in the MAP in response to the IC injection of imatinib (Fig. 1D,E). The time course of the increase in the ICP and decrease in the MAP in response to the IC injection of imatinib $10 \mathrm{mg} / \mathrm{kg}$ was similar (Fig. 1D,E). These data indicate that the tyrosine kinase inhibitor had significant erectile and systemic hypotensive activity in the rat.

The role of NOS and NO in mediating the erectile response to imatinib was also investigated. After treatment with the NOS inhibitor L-NAME $50 \mathrm{mg} / \mathrm{kg} \mathrm{IV}$, a dose that inhibited the increase in ICP in response to cavernosal nerve stimulation by $>85 \%$ (67 \pm 4 vs $12 \pm 3 \mathrm{~mm} \mathrm{Hg} ; P<.05$, paired $t$ test), the increase in the ICP and AUC in response to the IC injection of imatinib after L-NAME treatment was not altered compared with the responses in the control rats $(P>.05$ for all doses, paired $t$ test; Fig. 2A). The effect of cavernosal nerve crush injury on the response to imatinib was also investigated. The increase in the ICP in response to the IC injection of imatinib $10 \mathrm{mg} / \mathrm{kg}$ was not altered by the nerve crush injury, which reduced the response to cavernosal nerve stimulation at $16 \mathrm{~Hz}$ by $92 \%(64 \pm 3$ vs $5 \pm$ $1 \mathrm{~mm} \mathrm{Hg} ; P<.05$, paired $t$ test; Fig. 2B). The results of these experiments indicate that the increase in the ICP in response to IC injection of imatinib was not dependent on NOS or NO release or tonic nerve activity in the cavernosal nerves.

The IC injection of imatinib decreased the MAP at all doses studied. Also, the systemic vascular effects of the tyrosine kinase inhibitor were investigated in experiments in which IV imatinib was injected. In these experiments, the cardiac output was measured and the systemic vascular resistance determined. The IV injection of imatinib in doses of $0.3-30 \mathrm{mg} /$ $\mathrm{kg}$ produced dose-related decreases in the MAP ( $5 \pm 1$ to $53 \pm 2 \mathrm{~mm} \mathrm{Hg} ; P<.05$, ANOVA) without causing significant changes in cardiac output ( $P<.05$, ANOVA; Fig. $3 \mathrm{~A})$. The 
systemic vascular resistance decreased $2 \%-48 \%$ at imatinib doses of $0.3-30 \mathrm{mg} / \mathrm{kg}(P<.05$, ANOVA; Fig. 3A). The decreases in systemic arterial pressure and systemic vascular resistance in response to IV injection of imatinib were not altered by administration of LNAME $50 \mathrm{mg} / \mathrm{kg}$ IV $(P>.05$, paired $t$ test; Fig. 3A,B). The results of these studies indicate that imatinib has marked vasodilator activity that is not dependent on NO in the systemic vascular bed.

The erectile and systemic responses to imatinib and the NO donor SNP were compared (Fig. 4). Imatinib was $>4$ orders of magnitude less potent than SNP in its ability to increase the ICP when injected IC (Fig. 4A). However, it had efficacy similar to that of SNP because both agents at the highest doses studied increased the ICP by approximately $50 \mathrm{~mm} \mathrm{Hg}$ (Fig. 4A). Imatinib was approximately 3 orders of magnitude less potent than SNP in its ability to decrease the MAP when injected IV but had similar efficacy because both agents decreased the MAP by approximately $50 \mathrm{~mm} \mathrm{Hg}$ when injected at the highest dose studied $(P>0.05, t$ test; Fig. 4B). The results of these studies indicate that imatinib has significant erectile and systemic hypotensive activity in the rat and similar efficacy to the NO donor SNP in that similar apparent maximal responses were observed, although it was less potent than SNP.

\section{COMMENT}

The results of the present study have documented that imatinib has significant erectile and systemic vasodilator activity in the rat. Our results have shown that IC injections of imatinib produce dose-related increases in the ICP, ICP/MAP ratio, AUC, and response duration. The increase in ICP in response to imatinib was rapid in onset and short in duration and was similar to the response to nilotinib, another tyrosine kinase inhibitor used to treat chronic myelogenous leukemia. ${ }^{12}$ The response to imatinib was not altered by administration of the NOS inhibitor L-NAME or cavernosal nerve crush injury. The results with the NOS inhibitor L-NAME and nerve crush injury suggest that erectile responses to imatinib are not dependent on endogenous NO release nor on tonic nerve activity in the cavernosal nerves. The dose-response curve for the increase in the ICP in response to imatinib was $>4 \log$ units to the right of the dose-response curve for the NO donor SNP. However, both agents produced similar large increases in the ICP at the highest dose studied. These data indicate that imatinib is less potent than SNP but has similar efficacy in increasing the ICP. The IC injection of imatinib decreased the MAP. The effect of imatinib on the systemic vascular bed was investigated in experiments in which the cardiac output was measured and changes in systemic vascular resistance were assessed. In these experiments, IV injection of imatinib produced dose-related decreases in the MAP. Because the cardiac output was not changed, these results indicate that imatinib decreases systemic vascular resistance by $2 \%-48 \%$ when injected in IV doses of $0.3-30.0 \mathrm{mg} / \mathrm{kg}$. The systemic vasodilator responses to IV injection of imatinib were rapid in onset and short in duration, indicating that imatinib has significant vasodilator activity in the systemic vascular bed of the rat, although it is less potent than SNP.

Imatinib is a tyrosine kinase inhibitor exhibiting activity against the oncogenes fusion gene BCR-ABL1 and is effective in the treatment of chronic myelogenous leukemia. ${ }^{13}$ Imatinib was originally developed as a PDGF inhibitor. It is a potent inhibitor of PDGF receptor (PDGFR) autophosphorylation and has been shown to inhibit a number of other tyrosine kinases similarly to nilotinib. ${ }^{14}$ Imatinib has been shown to have potent vasorelaxant activity in isolated arteries from the lung studied in a tissue bath and has been useful in the treatment of pulmonary hypertension in rodent models and humans. ${ }^{9,15-18}$ It has been suggested that inhibition of the PDGFR and Src kinases might mediate the beneficial effect of imatinib and related tyrosine kinase inhibitors on the vascular remodeling that occurs in pulmonary hypertension. ${ }^{16}$ 
The mechanism by which imatinib induces erection and vasodilation in the systemic vascular bed is uncertain. Imatinib is a potent inhibitor of PDGFR signaling, and it is possible that a mechanism related to PDGFR signaling might be involved in the smooth muscle relaxing actions of imatinib. In addition to the vasodilator actions of imatinib in the systemic vascular bed and isolated pulmonary arteries, imatinib has been shown to relax isolated smooth muscle preparations from the guinea pig urinary bladder, human myometrium, and prostate and cavernosal tissue of the rat. ${ }^{4-6,19}$ Imatinib has been shown to have inhibitory effects on guinea pig and overactive human detrusor muscle, and it has been suggested that these inhibitory effects are mediated by blocking KIT receptors. ${ }^{4,20}$ It has also been hypothesized that KIT receptor blockade mediates the inhibition of spontaneous rhythmic contractions of the human uterus and intestinal smooth muscle and in rabbit myometrial strips. ${ }^{7,8}$ It has been reported that the cytokine PDGF increases the vasoconstrictor tone and intracellular calcium levels in the isolated rabbit ear artery. ${ }^{21}$ Because 3 different tyrosine kinase inhibitors have potent inhibitory effects on PDGF and have vasodilatory effects in isolated pulmonary arteries, it is possible that tonic PDGF release and activation of PDGFRs in blood vessels could increase the intracellular calcium concentration and induce vasoconstriction in the systemic vascular bed that is antagonized by tyrosine kinase inhibitors such as imatinib. ${ }^{9}$ It is, therefore, possible that inhibition of PDGFR signaling by imatinib and nilotinib might induce penile erection and peripheral vasodilation, although another mechanism could not be ruled out. Imatinib and nilotinib have been shown to inhibit autophosphorylation of a number of tyrosine kinases, including KIT, discoidin domain-containing receptor-1, discoidin domain-containing receptor-2, colony-stimulating factor-1 receptor, colony-stimulating factor-2 receptor. It is possible that inhibition of tyrosine kinase signaling, in addition to PDGF signaling, could be involved in mediating the substantial erectile and systemic vasodilator responses to imatinib in the rat. ${ }^{22}$

\section{Study Limitations}

In respect to the limitations in the present study, the results with imatinib are speculative and were based on the assumption that inhibition of a tyrosine kinase signaling pathway mediates the increase in the ICP and the decrease in the MAP. Although many studies have demonstrated that imatinib is an inhibitor or antagonist of tyrosine kinase signaling, the hypothesis that this agent might have agonist activity could not be ruled out. The findings with nilotinib, another tyrosine kinase inhibitor, support our hypothesis. However, endogenous ligands, such as PDGF, which might mediate detumescence and systemic vasoconstriction, have not been identified, and another mechanism involving agonism, rather than antagonism, could be involved. Experiments with other potent more selective tyrosine kinase inhibitors are needed, along with the identification of the growth factor or cytokine, such as PDGF, that activates the tyrosine kinase receptor in the corporal and vascular smooth muscle that is blocked by imatinib. Moreover, the inhibition of a negative regulatory pathway would be expected to produce an agonist-type response.

\section{CONCLUSION}

The results of the present study have shown that the tyrosine kinase inhibitor imatinib has substantial erectile and systemic vasodilator activity that is not dependent on NOS or NO. These data suggest that inhibition or antagonism of a tonic tyrosine kinase signaling pathway could be involved in mediating a constitutively active vasodilator mechanism in the corporal and systemic vascular smooth muscle in the rat, although another mechanism of action could not be ruled out. 


\section{References}

1. Hubbard SR, Miller WT. Receptor tyrosine kinases: mechanisms of activation and signaling. Curr Opin Cell Biol. 2007; 19:117-123. [PubMed: 17306972]

2. Schiffer CA. BCR-ABL tyrosine kinase inhibitors for chronic myelogenous leukemia. N Engl J Med. 2007; 357:258-265. [PubMed: 17634461]

3. Min Y, He P, Wang Q, et al. The effects of the c-kit blocker Glivec on the contractile response of urinary bladder. J Surg Res. 2011; 171:e193-e199. [PubMed: 21962730]

4. Kubota Y, Biers SM, Kohri K, et al. Effects of imatinib mesylate (Glivec) as a c-kit tyrosine kinase inhibitor in the guinea-pig urinary bladder. Neurourol Urodyn. 2006; 25:205-210. [PubMed: 16425211]

5. Ozgur-Akdemir A, Demirturk K, Karabakan M, et al. Imatinib mesylate (Gleevec) as proteintyrosine kinase inhibitor elicits smooth muscle relaxation in isolated human prostatic tissue. Urology. 2011; 78:968e1-968.e6. [PubMed: 21872909]

6. Cretoiu SM, Simionescu AA, Caravia L, et al. Complex effects of imatinib on spontaneous and oxytocin-induced contractions in human non-pregnant myometrium. Acta Physiol Hung. 2011; 98:329-338. [PubMed: 21893472]

7. Popescu LM, Vidulescu C, Curici A, et al. Imatinib inhibits spontaneous rhythmic contractions of human uterus and intestine. Eur J Pharmacol. 2006; 546:177-181. [PubMed: 16919263]

8. Hutchings G, Deprest J, Nilius B, et al. The effect of imatinib mesylate on the contractility of isolated rabbit myometrial strips. Gynecol Obstet Invest. 2006; 62:79-83. [PubMed: 16601347]

9. Abe K, Toba M, Alzoubi A, et al. Tyrosine kinase inhibitors are potent acute pulmonary vasodilators in rats. Am J Respir Cell Mol Biol. 2011; 45:804-808. [PubMed: 21378262]

10. Pankey EA, Bhartiya M, Badejo AM Jr, et al. Pulmonary and systemic vasodilator responses to the soluble guanylyl cyclase activator, BAY 60-2770, are not dependent on endogenous nitric oxide or reduced heme. Am J Physiol Heart Circ Physiol. 2011; 300:H792-H802. [PubMed: 21217076]

11. Lasker GF, Pankey EA, Allain AV, et al. Analysis of erectile responses to BAY 41-8543 and muscarinic receptor stimulation in the rat. J Sex Med. 2013; 10:704-718. [PubMed: 22989320]

12. Weisberg E, Manley PW, Breitenstein W, et al. Characterization of AMN107, a selective inhibitor of native and mutant Bcr-Abl. Cancer Cell. 2005; 7:129-141. [PubMed: 15710326]

13. Druker BJ, Sawyers CL, Kantarjian H, et al. Activity of a specific inhibitor of the BCR-ABL tyrosine kinase in the blast crisis of chronic myeloid leukemia and acute lymphoblastic leukemia with the Philadelphia chromosome. N Engl J Med. 2001; 344:1038-1042. [PubMed: 11287973]

14. Hwang RF, Yokoi K, Bucana CD, et al. Inhibition of platelet-derived growth factor receptor phosphorylation by STI571 (Gleevec) reduces growth and metastasis of human pancreatic carcinoma in an orthotopic nude mouse model. Clin Cancer Res. 2003; 9:6534-6544. [PubMed: 14695158]

15. Ghofrani HA, Seeger W, Grimminger F. Imatinib for the treatment of pulmonary arterial hypertension. N Engl J Med. 2005; 353:1412-1413. [PubMed: 16192491]

16. Schermuly RT, Dony E, Ghofrani HA, et al. Reversal of experimental pulmonary hypertension by PDGF inhibition. J Clin Invest. 2005; 115:2811-2821. [PubMed: 16200212]

17. Ghofrani HA, Morrell NW, Hoeper MM, et al. Imatinib in pulmonary arterial hypertension patients with inadequate response to established therapy. Am J Respir Crit Care Med. 2010; 182:11711177. [PubMed: 20581169]

18. Souza R, Sitbon O, Parent F, et al. Long term imatinib treatment in pulmonary arterial hypertension. Thorax. 2006; 61:736. [PubMed: 16877696]

19. Gur S, Kadowitz PJ, Hellstrom WJ. A protein tyrosine kinase inhibitor, imatinib mesylate (Gleevec), improves erectile and vascular function secondary to a reduction of hyperglycemia in diabetic rats. J Sex Med. 2010; 7:3341-3350. [PubMed: 20584116]

20. Biers SM, Reynard JM, Doore T, et al. The functional effects of a c-kit tyrosine inhibitor on guinea-pig and human detrusor. BJU Int. 2006; 97:612-616. [PubMed: 16469036]

21. Hughes AD. Increase in tone and intracellular $\mathrm{Ca} 2+$ in rabbit isolated ear artery by platelet-derived growth factor. Br J Pharmacol. 1995; 114:138-142. [PubMed: 7712009] 
22. Manley PW, Stiefl N, Cowan-Jacob SW, et al. Structural resemblances and comparisons of the relative pharmacological properties of imatinib and nilotinib. Bioorg Med Chem. 2010; 18:69776986. [PubMed: 20817538] 
A
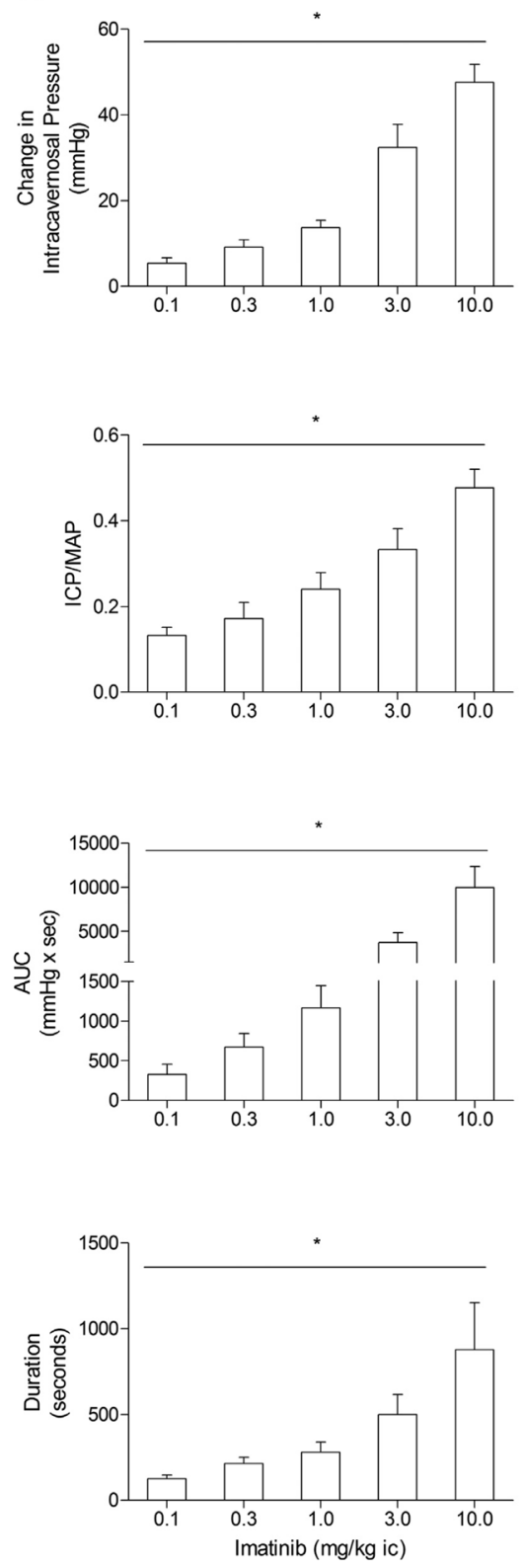

B

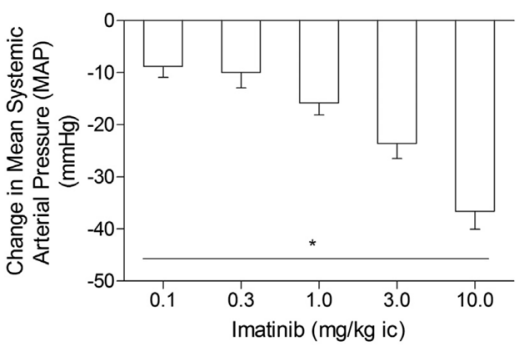

C

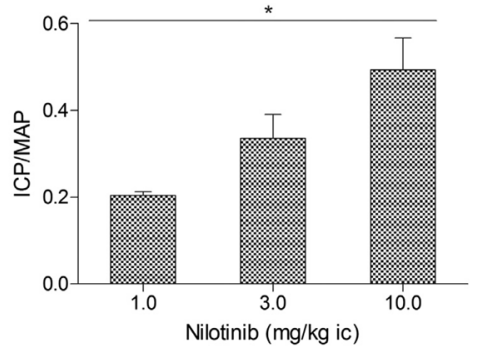

D
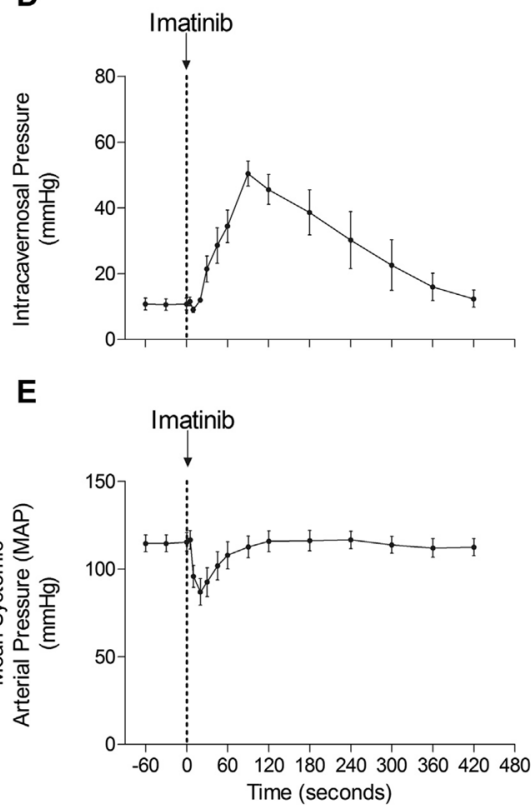

Figure 1.

(A) Bar graph showing peak change in intracavernosal pressure and changes in intracavernosal pressure/mean systemic arterial pressure ratio (ICP/MAP), area under curve (AUC), and duration in response to intracavernosal injection of imatinib $0.1-10.0 \mathrm{mg} / \mathrm{kg}$. (B) Bar graph showing decrease in MAP in response to intracavernosal (ic) injection of imatinib in doses of $0.1-10 \mathrm{mg} / \mathrm{kg}$. (C) Bar graph showing changes in ICP/MAP ratio in response to intracavernosal (ic) injection of nilotinib $1-10 \mathrm{mg} / \mathrm{kg}$. Line graphs showing time course of (D) increase in ICP and (E) decrease in MAP in response to intracavernosal injection of imatinib $10 \mathrm{mg} / \mathrm{kg}$. $\mathrm{n}$, number of rats. ${ }^{*} P<.05$, analysis of variance. 

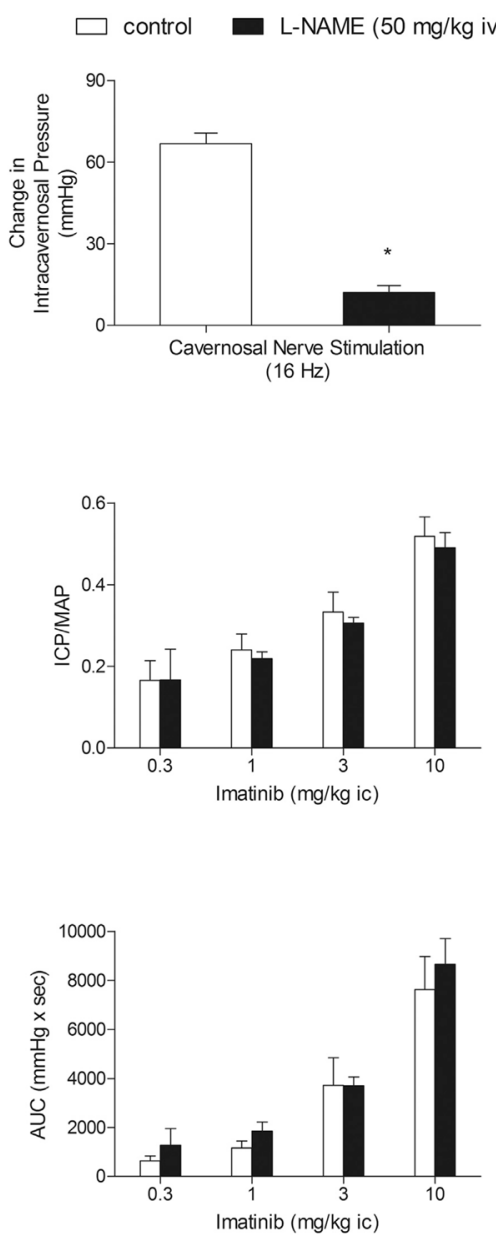

B

$\mathrm{n}=4$
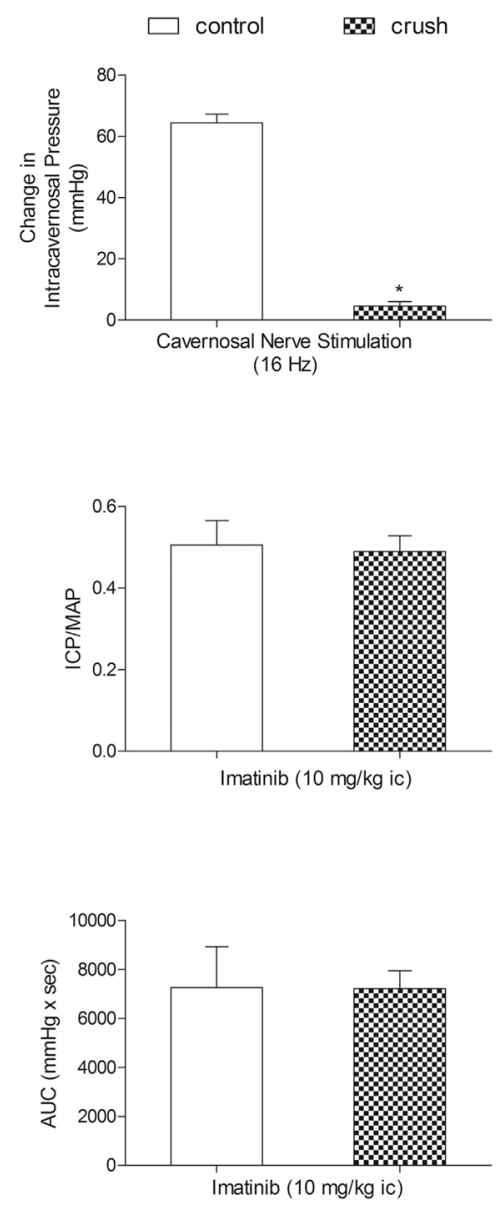

Figure 2.

(A) Bar graphs showing effect of nitric oxide synthase inhibitor NG-nitro-L-arginine methyl ester (L-NAME) $50 \mathrm{mg} / \mathrm{kg}$ intravenously on increase in intracavernosal pressure (ICP) in response to cavernosal nerve stimulation at $16 \mathrm{~Hz}$, increase in ICP/mean systemic arterial pressure (MAP) ratio in response to intracavernosal (ic) injection of imatinib $0.3-10.0 \mathrm{mg} /$ $\mathrm{kg}$, and total erectile response (area under curve [AUC]) induced by intracavernosal injection of imatinib 0.3-10.0 mg/kg. (B) Bar graphs showing effects of cavernosal nerve crush injury on increase in ICP in response to cavernosal nerve stimulation at $16 \mathrm{~Hz}$, increase in ICP/MAP ratio in response to intracavernosal injection of imatinib $10 \mathrm{mg} / \mathrm{kg}$, and total erectile response (area under curve $[\mathrm{AUC}]$ ) induced by intracavernosal injection of imatinib $10 \mathrm{mg} / \mathrm{kg}$. n, number of experiments. ${ }^{*} P<.05$, paired comparison. 

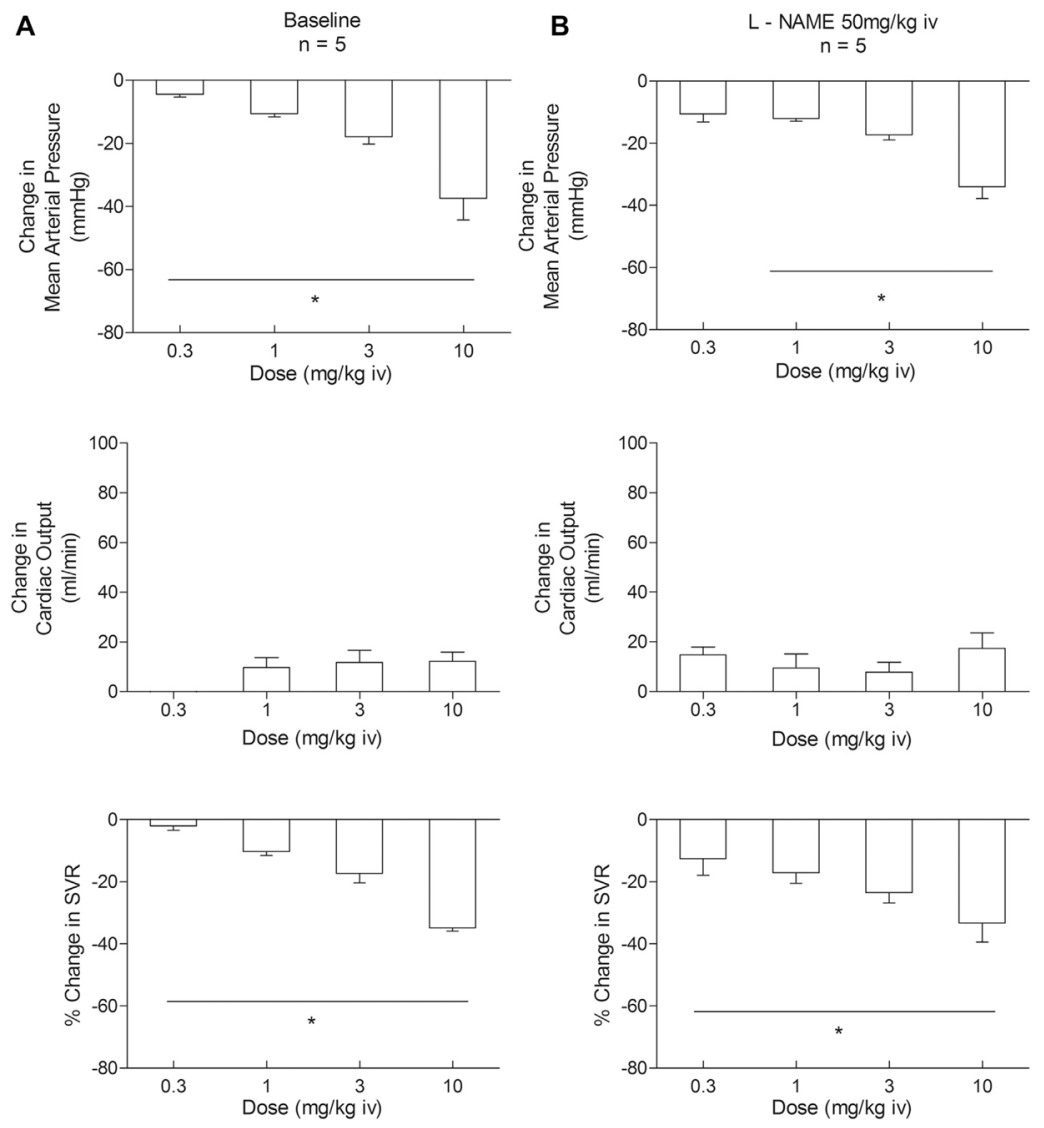

Figure 3.

Bar graphs showing effect of intravenous (iv) injections of imatinib $0.3-30.0 \mathrm{mg} / \mathrm{kg}$ on change in mean arterial pressure, change in cardiac output, and percentage of change in systemic vascular resistance (SVR) (A) under control conditions and (B) after treatment with nitric oxide synthase inhibitor NG-nitro-L-arginine methyl ester $(50 \mathrm{mg} / \mathrm{kg}$ iv). $\mathrm{n}$, number of experiments. $* P<.05$, analysis of variance. 

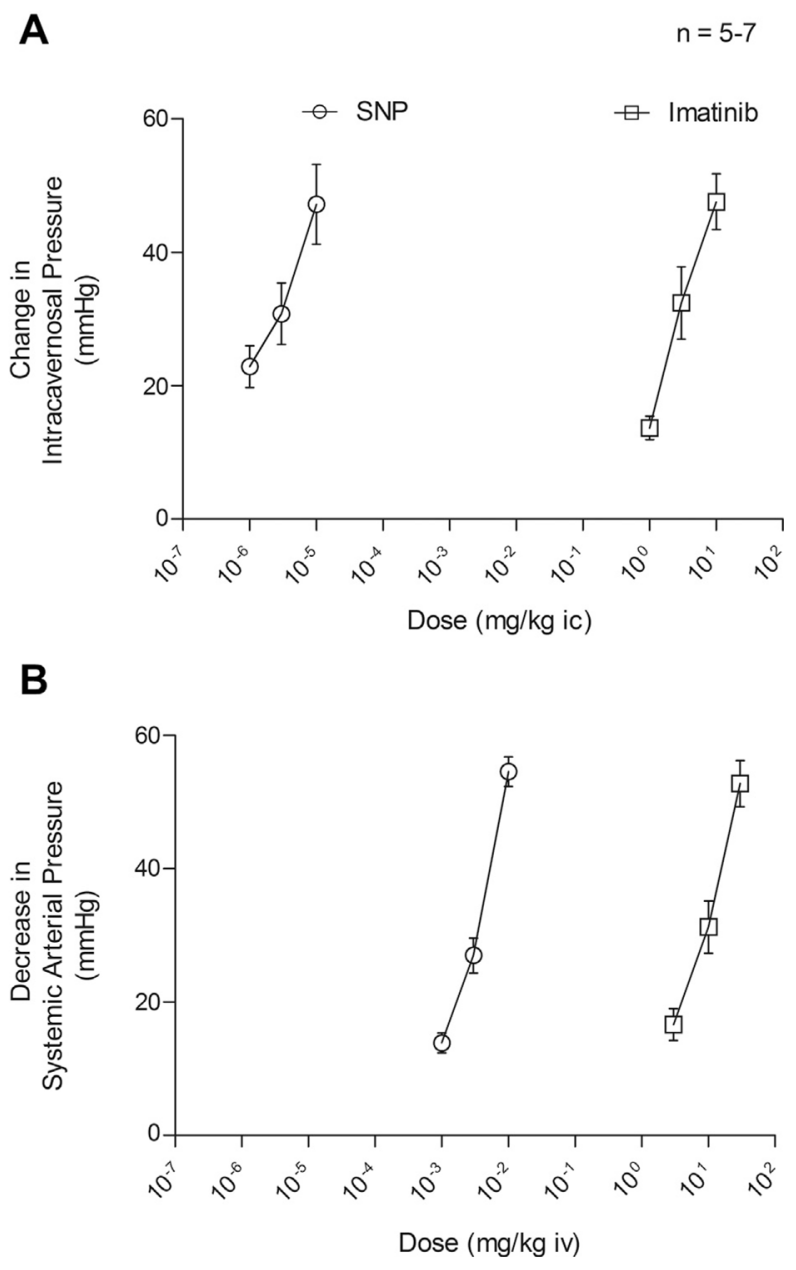

Figure 4.

Line graphs comparing dose-response curves for (A) intracavernosal (ic) injections of sodium nitroprusside (SNP) $(1,3$, and $10 \mu \mathrm{g} / \mathrm{kg})$ and imatinib $(1,3$, and $10 \mathrm{mg} / \mathrm{kg})$ on changes in intracavernosal pressure and (B) intravenous (iv) injections of $\operatorname{SNP}(1,3$, and 10 $\mu \mathrm{g} / \mathrm{kg})$ and imatinib $(1,3$, and $10 \mathrm{mg} / \mathrm{kg}$ ) on changes in mean systemic arterial pressure. $\mathrm{n}$, number of experiments. 